\title{
Everyone Vegetarian, World Enriching
}

\author{
John Y. Wu \\ Pathology Department, Visalia Pathology Medical Group, Visalia, USA \\ Email: wutulare@yahoo.com \\ Received 18 March 2014; revised 18 April 2014; accepted 25 April 2014 \\ Copyright (C) 2014 by author and Scientific Research Publishing Inc. \\ This work is licensed under the Creative Commons Attribution International License (CC BY). \\ http://creativecommons.org/licenses/by/4.0/

(c) (i) Open Access

\begin{abstract}
This essay advocates global vegetarian diet. Firstly, seven personal health benefits and four global benefits of vegetarian dinners are specified to enrich the entire globe, and then, secondly, I explore concretely how to overcome internal hurdle and external hurdle, so as to effectively propagate vegetarian dinners throughout the world. Everyone wins, including animals!
\end{abstract}

Keywords

Vegetarian; Personal Benefits; Global Benefits; Animal Suffering; Hurdle; Win

\section{Introduction}

Do you know what a single thing is, just doing that one simple thing each day, to make each of us feel more energized, live longer, feed the hungry, end animal suffering, and save our planet earth from pan-destruction? It is to become a vegetarian! This change in daily routine diet would literally revolutionize the whole world. The following pages elucidate this fact, simple yet stunning, personal and global.

Let us take just one point mentioned above, our own health to be overhauled by diet change. Imagine a person waking up on Monday morning, driving to McDonald's to get a sausage egg McMuffin; he eats it and heads quickly to work. For lunch, he grabs a Carl's Jr. bacon cheeseburger and fries, and for dinner he decides on a couple of chili dogs. He thinks nothing of all this until he goes to his doctor for a regular follow-up appointment to get the lab results of his cholesterol level. It is high: 270. His doctor informs him of the risk for clogged arteries in the heart, brain, kidney, everywhere. Ouch!

The reason is simple. We humans are not created to ever tear apart living animals to eat their flesh. Cats were created to eat meat; they have four sharp, pointy fangs, none for chewing as our molars do. Our incisor teeth are not fangs. Our digestive system is not designed to eat meat, so earliest man must have observed carnivores such as the cat eating meat and copied them (http://howtobecomeavegetarian.org).

I now hear someone say, "All food stuff has benefits and harms, right? Doesn't the essence of dieting lie in managing diet fittingly, not to choose vegetarian over meat diet? In fact, Dr. Atkins advocates eating more meat 
protein and less vegetable carbohydrates to lose weight ${ }^{1}$.” This is a fair enough objection. Let us take up on this challenge and consider what we have mentioned above, one by one. We can then see how "managing diet" fittingly goes to vegetarianism. First, in Section 2 below, we go into seven health benefits, and then four global benefits, of vegetarian diet. We would then in Section 3 tackle two hurdles, internal (personal taste) and external (ubiquitous preference of meat), to propagate vegetarian dinners worldwide.

\section{Vegetarianism: Seven Health Benefits, Four Global Benefits}

Now we go into the excitements of benefits of vegetarian diet, ONE, its seven health benefits, then TWO, four benefits to the entire globe, and on their basis THREE, compare meat diet with vegetarian diet. This probe would fittingly respond to the challenge to "manage diet without choosing either vegetarian diet or meat diet".

\subsection{ONE: Vegetarianism: Seven Health Benefits}

\subsubsection{Vegetarian Diet Has No Less than Seven Benefits}

1) We will live longer as vegetarians:

If we switch from the standard American diet to a vegetarian meal, we can add about 13 healthy years more to our life (Roizen, 2001). Residents of Okinawa in Japan have the longest life expectancy in the world, according to a 30 year study of more than 600 Okinawa people at ages 100 or older. They were vegetarians ${ }^{2}$.

2) We will have more energy as vegetarians:

Whole grains, legumes, fruits and vegetables have high complex carbohydrates that supply the body with plenty of energizing fuel. Too much fat from meat in the blood results in arteries not opening properly to lacking supply of enough oxygen to our muscles. What is the result? We crash and feel tired. Our alarm clock becomes our enemy!

3) We will be more "regular" as vegetarians:

Meat contains no fiber. Eating more vegetables means eating more fiber which pushes waste smoothly out of the body. Fiber lowers the risk of constipation, hemorrhoids, and diverticulitis.

4) We will ward off diseases as vegetarians:

"We need nutrition in meat that vegetables lack," some of us may say. Now we can be reassured. The vegetarian diet has the single most effective nutrition to stop progression of coronary artery disease, even to prevent it entirely. Cardiovascular disease is the leading cause of death in the US, killing one million Americans each year. Sorry, Dr. Atkins, animal fat and its cholesterol is the cause. Meat is high in fat and high in cholesterol. Vegetables are low in fat and have no cholesterol.

"Can't eggs and fish count as vegetarian diet? Some Buddhists consume them.” Vegetarian diets lack cholesterol. There are varieties of vegetarians. Vegan vegetarians do not eat animal byproducts such as cream cheese, hard cheese, ice cream, and eggs. Lacto-ovo vegetarians eat eggs and dairy products such as milk and cheese. Ovo vegetarians eat eggs but no dairy products

(http://www.health.harvard.edu/newsletters/Harvard_Womens_Health_Watch/2009/October/becoming-a-vegeta rian). Fish does contain healthy omega 3 fatty acids which is heart healthy. Still, the same can be found in flax seeds. In all, vegetarian diet is the healthiest diet.

5) We will keep our weight down as vegetarians:

According to the Centers for Disease Control (CDC) in the USA, 64\% of adults and 15\% of children aged 6 to 19 are overweight. Dean Ornish, M.D., President of Preventative Medicine Research, found that overweight people who followed a low fat, vegetarian diet, lost an average of 24 pounds the first year and kept off that

\footnotetext{
${ }^{1}$ Robert Atkins in Dr Atkins Diet Revolution, New York: Bantam Books (1972) promoted eating unlimited amounts of fatty meats and cheeses. The Atkins diet involves limited intake of carbohydrates to switch the body's metabolism from using glucose as energy to using stored fat as energy. Dr Robert Eckel of the American Heart Association says that high protein, low carbohydrate diets puts people at risk of heart disease ("What is the Atkins Diet? Read the Expert Review" www.webmd.com archived from the original on January 17, 2010). A long-term study published in the New England Journal of Medicine in 2006 found that while women on low carb diets were generally healthier than those on high-carbohydrate diets, women eating more protein and fat from vegetable sources, rather than animal sources, had a lower risk of heart disease (msnbc.msn.com November 8, 2006. Carbs may be worse for heart than fatty foods. Long-term study eases concerns about risk of Atkins, other low-carb diets). As usual, scientific community is polite and mild, but such guarded responses clearly cipher their overall negative impressions on Dr. Atkins.

${ }^{2}$ See vegetariantimes.com. Sally Beare cites Okinawa as the first of "the world's five longevity hot spots" in her 50 Secrets of the World's Longest Living People, New York: MJF Books ( 2006) pp. 1-8; Okinawa folks are "consuming plenty of fresh vegetables and fruit, grown organically and locally”, not eating "much meat or dairy” (p. 8).
} 
weight five years later. They lost the weight without counting calories or carbs, measuring portions or feeling hungry.

6) We will ward off cancers as vegetarians:

Countries that practice a vegetarian diet such as China have low breast cancer rates. In Japan, women who follow traditional plant-based diets are 8 times less likely to develop breast cancer than those Japanese women who follow Western-style meat-based diets.

In a recent Harvard study involving tens of thousands of men and women, those who regularly consumed meat increased their risk of colon cancer by $300 \%$. For men, daily meat consumption increased their risk of prostate enlargement three times. Consuming milk regularly doubles this risk, and failure to consume adequate amounts of vegetables daily, nearly quadruples the risk. Vegetarians have more natural killer cells which are a type of white blood cell that attacks cancer cells before they populate (http://www.howtobecomeavegetarian.org/Humans-Didn\%27t-Always-Eat-Meat.html).

7) Animal Suffering is stopped by vegetarian diet:

Animals have feelings and emotions just as we humans. At one year of age pigs and sheep are capable of logical thought and are more intelligent than human babies 6 weeks old (http://giveusahome.co.uk/articles/vegetarianism.htm). Chickens are found to be more intelligent than dogs, worry about the future, and perform tasks that monkeys cannot. If not many of us eat dog, why do we eat chickens? Fish also experience pain when trapped, etc. Any animals with eyes are sentient. We should not eat them. Thus animal slaughter is felt tragically as much as human slaughter humanly felt. Our vegetarian diet will spare animals altogether (http://www.vegetariantimes.com/article/why-go-veg-learn-about-becoming-a-vegetarian/).

Before slaughter all animals experience tremendous fear, pain and anxiety. Farmers use tranquilizers before killing animals. But hormones of depressed animals remain in their flesh. In the US alone, 10 billion animals are slaughtered for human consumption each year. Globally, the number of deaths exceeds 65 billion (more than 6 million every hour). The number of fish and other aquatic animals killed each year is much greater.

In addition, most land animals for meat spend their entire lives in crates or stalls so small that they cannot even turn around. Farm animals are not protected from cruelty under the law. In fact, the majority of state anticruelty laws specifically exempt farm animals from basic humane protection. Farmers also use harmful growth hormones and antibiotics which remain in their flesh after death, and consumed by humans. The average number of land animals killed per person per year in the US is 28; this number far exceeds the rest of the world at 6 .

In all, we have just gone through no less than seven health benefits for humans and animals, of vegetarian diet. This is already quite impressive, isn't it? Now, vegetarian diet gives us more benefits yet, extending to the entire globe.

\subsection{TWO: Vegetarianism: Four Global Benefits}

Incredibly, our private vegetarian diet has effects far beyond our privacy to spread throughout the whole world. Now, let us consider four Global Benefits of vegetarian diet (http://www.britishmeat.com/49.htm).

1) Our vegetarian diet will help reduce famine:

If all the grain currently fed to livestock were consumed directly by people, the number of people who could be fed would be nearly 800 million, says David Pimentel, professor of Economics at Cornell University. It is estimated that globally, 925 million people are hungry. Hunger is due to protein and calorie deficiency (http://worldhunger.org/articles/Learn/world\%20hunger\%20facts\%202002.htm).

This means that vegetarian diet increases feeding of an additional $86 \%$ of the world's hungry people, reducing almost $90 \%$ of world hunger.

2) Our vegetarian diet will help conserve non-renewable fossil fuel:

It takes 78 calories of fossil fuel to produce 1 calorie of beef protein but only 1 calorie of fossil fuel for 1 calorie of soybeans which are the world's most fertile and proficient food stuff.

3) Our vegetarian diet will help conserve water:

It takes up to 15 times as much as water to produce animal protein as it does plant protein. 25 gallons of water is needed to produce a pound of wheat; 5000 gallons is needed for a pound of beef. The benefit of conserving water much outweighs the doubtful and miniscule superiority of meat over vegetable, as the next subsection would show.

4) Our vegetarian diet will conserve soil and save our forests: 
Tropical forests in Brazil and other tropic regions are destroyed daily to create more acreage to raise livestock. Every quarter pound of meat consumes 55 sq. feet of tropical rainforest. 85\% top soil is lost to raise livestock. 26 million acres of US forest are cleared to produce our meat diet. 1000 species per year are extinct due to destruction of rainforest for meat grazing.

The above statistical information alarms us about how ecologically far-reaching impacts our casual switch to vegetarian diet would produce. It simply boggles our mind.

\subsection{THREE: Meat Compared with Vegetables}

Now, we can launch a direct "frontal attack" on meat diet by comparing meat with vegetables. Meat content is here compared with vegetable content (http://www.britishmeat.com/49.htm).

Five points are here to decisively show how superior vegetable diet is to meat in many senses. Besides, the comparisons below are a tip in an iceberg. We have many more, of course.

One, meat is high in both fat and cholesterol, major sources of various sicknesses, whereas vegetables are low in fat and have no cholesterol at all.

Two, meat contains agricultural chemicals such as pesticides and herbicides. Being lower in the food chain, plants contain much lower levels of these chemicals. Meat contains over 20,000 different livestock drugs such as sterols, antibiotics and growth hormones. Plants do not have these drugs at all.

Three, meat contains a host of harmful bacteria, viruses, worms, and other parasites, whereas plants do not have as many nor as dangerous of organisms. Meat can include the tail, head, feet, rectum and spinal cord. Since sausage can contain ground pig intestine it may include feces as well

(http://giveusahome.co.uk/articles/vegetarianism.htm).

Meat contains animal toxins such as adrenaline, uric acid, lactic acid. The blood and urine of meat is what constitutes the flavor of hamburger (http://www.britishmeat.com/49.htm). "Delicious meat" means "foul harmful contents".

Four, except for the B-complex vitamins, meat is completely vitamin-deficient. In addition, meat is also deficient in fiber and carbohydrates essential for health. In contrast, vegetables have no such deficiencies; there are no nutrients necessary for optimal human functioning which cannot be found in plant food. In fact, many of the world's most successful and strongest athletes are vegetarians.

Five, overall, meat is much more expensive than vegetables. Why do we spend more money on less nutritious and more harmful food/meat is completely beyond our sanity.

Now, to clinch the above, here are some recapitulations of the whole recommendation of worldwide vegetarian diet for us all (vegecyber.com/others/about vegetarianism.shtml). Deaths due to hunger this year is 20 million and 10 million can be saved by using land freed if US people reduced just $10 \%$ of meat intake (http://www.health.harvard.edu/newsletters/Harvard_Womens_Health_Watch/2009/October/becoming-a-vegeta $\underline{\text { rian)}}$.

One meat meal needs 3 times as much fossil fuel as no-meat meal needs; fossil fuel produces carbon dioxide that contributes to the greenhouse effect. 78 calories of fossil fuel gets 1 calorie of protein of beef, 2 calories are needed to get 1 calorie of protein of soybeans. Eating meat daily increases the risk of breast cancer 3.8 times; eating meat and dairy product increases the risk of prostate cancer 3.6 times. Risk of heart attack is reduced $90 \%$ if we eat no meat or dairy product. Besides, $80 \%$ of cancer is preventable by vegetarian diet (http://www.yale.edu/ycvs/10reasons.html).

Now listen to these people. “Animals are my friends_and I don't eat my friends” (George Bernard Shaw). "Martin Luther King taught us all nonviolence. I was told to extend nonviolence to the mother and her calf" (Dick Gregory). "I would not eat if no one kills the animal," said the meat eater. "I would not kill if no one eats the animal," said the butcher. "Cruelty to animals can become violence to humans" (Ali MacGraw). "Compassion is the foundation of everything good. If you carry compassion to marketplace and dinner table, you can make your life really count” (Rue McClanahan).

"A man can be healthy without killing animals for food; so, if he eats meat he participates in taking animal life merely for his appetite" (Leo Tolstoy). "I have reached zero tolerance for the cruelty against our animal brothers. If we are to nurture our culture, let's begin with the animals who have been nothing but our beasts of burden for so long" (Riki Rockett). "Since visiting the abbatoirs [slaughterhouses] of South France, I have stopped eating meat” (Vincent Van Gogh). 
"In all the round world of Utopia there is no meat. And it is impossible to find anyone who will hew a dead ox or pig. I can still remember as a boy rejoicing over closing of the last slaughterhouse" (H. G. Wells). "Nothing will benefit human health and increase chances for survival of life on Earth as much as the evolution to a vegetarian diet" (Albert Einstein). "I have no doubt that it is a part of the destiny of the human race, in its gradual improvement, to leave off eating animals" (Henry David Thoreau).

"The beef industry has contributed to more American deaths than all the wars of this century, all natural disasters, and all automobile accidents combined. If beef is your idea of 'real food for real people', you'd better live real close to a real good hospital” (Neal D. Barnard, M.D., President, Physicians Committee for Responsible Medicine). "People often say that humans have always eaten animals, as if this is a justification for continuing the practice. According to this logic, we should not try to prevent people from murdering other people, since this has also been done since the earliest of times" (Isaac Singer).

"The greatness of a nation and its moral progress can be judged by the way its animals are treated" (Mohandas Gandhi). "If [man] is not to stifle his human feelings, he must practice kindness towards animals, for he who is cruel to animals becomes hard also in his dealings with men. We can judge the heart of a man by his treatment of animals" (Immanuel Kant). "I am not interested to know whether vivisection produces results that are profitable to the human race or doesn't... The pain which it inflicts upon unconsenting animals is the basis of my enmity toward it, and it is to me sufficient justification of the enmity without looking further" (Mark Twain).

Now, you may know the imaginary person who went to McDonald's for a hamburger, and received health warning from his doctor, told at the beginning above-it's me, yours sincerely! I have lost 46 pounds since becoming a vegetarian and I never felt better every single day!

In summary, by becoming vegetarians we will [a] not only personally feel energized to live longer. We will [b] feed the hungry and end animal suffering, all over the world. Unbelievably, [c] the world itself is saved from ecological destruction by our private switch to vegetarian diet that is supposedly our private affair. No one would have realized such far-reaching consequences personal, among world species, and planetary, just by "me" becoming a vegetarian!

\section{How to Practice and Globally Propagate Vegetarian Dinners}

No more can be said. We simply must live as vegetarians! Here, however, we suddenly confront two hurdles to becoming vegetarians, an internal hurdle of "diet" as tasty dinner, and an external hurdle of inveterate preference for meat meals, dead-set worldwide. We must clear both hurdles to succeed in campaigning for everyone of us to become a vegetarian. It is not difficult to do; all we need is ingenuity to follow along with the trend of the times.

\subsection{ONE: Internal Hurdle: Diet as Tasty Dinner}

To begin with, we overhear some folks mumbling, "All this talk on vegetarian diet is objectively fine, but 'diet' is subjective personal enjoyment of tasting a dinner. We take oranges for health reason after enjoying the main course of a juicy steak. Tart oranges are nothing compared with succulent aroma of steak medium rare. After all, taste is no matter of dispute. If we enjoy steaks, we enjoy steaks.”

Well, we agree that diet is subjective tasting of a dinner, and if taste is not a matter of dispute, it is the matter of switchover. After taste-revolution, we can tastefully replace the stuffy aftertaste of a steak with clean aroma of oranges. "Orange air-freshener" on the market is no accident; orange refreshes our healthy life inside and out. Besides, happily, enjoying the sweet smell and flavor of fresh produce that continues to have living cells in it far surpasses the work of sawing into a piece or steak, watching the blood run, and having to gnaw at it with our teeth which are not equipped for the task.

"Do we have enough variety of vegetarian dinner-stuff, though? Are vegetable dinners as delicious as a meat dinner?” O yes, indeed! I am so glad you asked, pal. We have unlimited vegetarian dishes that are quite great delicacies (http://www.allrecipes.com) as thousands of vegetarian recipes. Grocery stores everywhere are stuffstocked with readymade vegetarian meals and items waiting for us all to discover and enjoy!

Besides tastefulness, we have many other reasons to become vegetarians! All these reasons shout one message to each of us: Vegetarianism makes literally everyone a winner in taste, in health, and in life, including animals, including the whole planet earth! 


\subsection{TWO: External Hurdle: Global Preference}

But, now, secondly, “our planet earth is filled with preference for meat meals, throughout world history,” you say. Well, we can warn people that, if looks are deceiving, taste also deceives, and thus hamburger and bad fat taste good to bring out our bad blood and bad urine. But it matters little.

Deception for deception, we can take advantage of meat-deception. We can say we do not even need to change our taste for meat. We can have meat substitutes and even dairy substitutes, including "ice creams" and "steak medium rare", all made of vegetables, and we can enjoy those various tastes of "meats" and "dairies", all in vegetables.

In fact, such vegetable-meats and vegetable-dairies have long been enjoyed by those Buddhists in China and in Japan! We have tons of vegetarian dinners that rival and often exceed meat tastes; we cannot tell their difference. Soy beans for example are quite nutritious and versatile; China has traditionally been exploiting it for ages, such as in soy sauce, tofu soft, medium, and hard, and many sorts of dried tofu for snacks, and so on.

Moreover, strategically, we see a worldwide opportunity to "convert" popular fast-food restaurants all over into popular haunting places for vegetarians. We can easily envision vegetarian McDonald's, vegetarian Burger Kings, vegetarian Pizza Huts, vegetarian Taco Bells, vegetarian Country Buffets, and the list goes on. The central open sesame here is to turn vegetarian dinners into an avid popular fashion with healthy gusto all over towns and villages. And it is not at all difficult to do.

In fact, vegetarianism is the world's fastest growing trend. There was a drop in meat demand in 2009 resulting in about a 5\% drop in the killing of animals. Besides, the majority of people worldwide are at present vegetarians, and meat-eaters are in the minority (http://vegecyber.com/others/about_vegetarianism.shtml).

Mass media can thus join with medical professionals to launch mass education to turn all dinner tables into vegetarian delicacies. Mass education has succeeded in abolishing tobacco smoking-as-chic; there is no reason why we cannot succeed in turning the whole planet earth into smiling flavorful vegetarianism with gusto.

So, what are we waiting for? Our whole vegetarian world is waiting for us all, just around the corner. We must reach out to hasten that world day to arrive among us. Again, no more can be said. We all simply must work in shouting enthusiasm toward living as vegetarians!

\section{Reference}

Roizen, M.F., \& La Puma, J. (2001). The Realage Diet: Make Yourself Younger with What You Eat. New York: HarperCollins Publishers. 